\title{
The history of dermatology, venereology and dermatopathology in different countries - Venezuela
}

\author{
Francisco Kerdel-Vegas1 and Jaime Piquero-Martín2* \\ ${ }^{1}$ Member of the Academies of Medicine and Science of Venezuela, Venezuela \\ ${ }^{2}$ Emeritus Professor, Graduate Institute of Biomedicine Dermatology Jacinto Convit, Venezuela
}

\begin{abstract}
About Venezuela
Venezuela is located to the north of the South American continent with almost one million square kilometers of land that comprises high mountains, plains, forests and deserts. Inhabited by American indigenous people since approximately fifteen hundred years before Christ, this land was discovered to the west by Christopher Columbus during his third trip in 1498, was conquered and colonized by Spain for three centuries, and Caracas, the capital city, was the seedbed for the movement of independence in the early Nineteenth Century. A complete generation of illustrious men including Simón Bolívar, Francisco de Miranda, José Antonio Páez and Antonio José de Sucre played an instrumental role in the consolidation of independence from Spain, waging a war that lasted for almost fifteen years, beginning in 1811 and ending with the Battle of Ayacucho in 1824 in Peruvian territory, thousands of kilometers away from Venezuela. This epic accomplishment left the country in a precarious situation that was followed by a series of civil wars fought among the military caudillos. The discovery and exploitation of oil after the second decade of the Twentieth Century gave rise to an economic boom that attracted a massive immigration into the country following World War II, mostly Spaniards, Italians and Portuguese nationals. Their hard work was pivotal to the modernization of the country that is still struggling to find the right path for its future development and prosperity.
\end{abstract}

\section{The Beginnings of Dermatology}

The native people suffered from a number of skin conditions including syphilis, yaws, pinta, impetigo and other infections such as tungiasis, pediculosis, scabies, myasis, leishmaniasis, poisoning and insect and reptile bites. The indigenous people used roots, stalks, flowers, resins, extracts and powders from various plants, including the guaiacum wood that was later used as specific treatment for syphilis in Spain and in other countries around the world. They used different balms for wound healing, in addition to a range of herbs.

The practice of medicine during the colonial times had considerable religious influence, though it was intended to be charity. Furthermore, since Venezuela was a captaincy-general, it was removed from all the advances in European medicine that came first to the viceroyalties. It was only in the middle of the Eighteenth Century when the "Protomedicato" (College of King's Physicians) was established under Royal License in Venezuela after 1777.

The study of medicine was initially introduced at the University of Caracas on October 10, 1763 at a time when the classical, HippocraticGalenic medicine gave way to the illustrated, rationalistic medicine.

\section{Academic Dermatology}

Like in any other branch of medicine, general practitioners were the ones that initially treated skin diseases. The first specialized dermatologist arrived in Venezuela in 1882. His name was Nicanor Guardia (18601898); he was trained at the Saint Louis Hospital in Paris. Although he did not accomplish great things in his area of specialization, he paved the way for the first group of Venezuelan doctors that went to the school of dermatology at the Saint Louis Hospital (Figure 1).

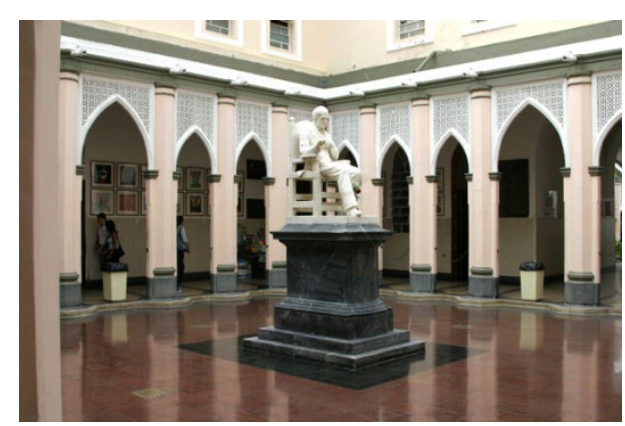

Figure 1. Saint Louis Hospital

The first general hospital with academic projection -Hospital Vargas de Caracas - was inaugurated on January 1st, 1891 where doctors began to practice under the concept of specialization. In 1903 Manuel Perez-Diaz (specialized in France at the Saint Louis Hospital of Paris) created the first Service of Dermatology at the Hospital Vargas and then the Chair of Clinical Dermatology was established on

Correspondence to: Jaime Piquero-Martin, Instituto de Biomedicina Jacinto Convit, Hospital Vargas, Caracas, Venezuela; E-mail: piquero1@gmail.com

Special Issue: Dermatology History in Different Countries

Nooshin Bagherani, M. D.

Dermatologist at Dr. Nooshin Bagheran's office, Taha Physicians' building, P.O.Box: 6414715878, Khoramshahr, Khuzestan Province, Iran; Email: nooshinbagherani@yahoo.com

Bruce R. Smoller, M. D.

Chair, Department of Pathology and Laboratory Medicine

Professor, Department of Pathology and Laboratory Medicine

Professor, Department of Dermatology

University of Rochester School of Medicine and Dentistry, USA

E-mail: smollerbrucer@uams.edu

Published: December 20, 2015 
December 30, 1908, at the School of Medicine of Caracas where he was appointed as the first professor. Two years later (1910), Dermatology became a mandatory subject for sixth year medical students. Manuel Pérez-Díaz's successor was Miguel Jiménez-Rivero who was then followed by Pablo Guerra, Martin Vegas, Leopoldo Briceño-Iragorry (for a short period of time), and in 1947 Carlos Julio Alarcón. The remarkable influence of the French school of dermatology of the Hospital Saint Louis of Paris through its students was interrupted by the Second World War; this event changed the Venezuelan tradition of pursuing medical graduate studies in France and switched to the United States (particularly New York City) where a new generation of dermatologists was trained: Jacinto Convit, Francisco Scannone, Luis Alberto Velutini, Eva Koves de Amini, JJ Henríquez-Andueza, Francisco Kerdel-Vegas, Mauricio Goihman, José Manuel Soto, Dolores Alfonzo de Pérez, Hugo Naranjo, and many others came to the US. Mention must be made of the influence that doctor José SánchezCovisa had on the practice of dermatology in Venezuela. In 1938, Dr. Martín Vegas invited Professor Sánchez-Covisa who had been professor and head of dermatology at the University of Madrid, to join the practice of dermatology after he was forced to emigrate and exile as a result of the political events in his motherland. In Venezuela he continued his already internationally renowned work as teacher and researcher. He was then appointed Technical Advisor of the Division of Venereal Diseases of the Ministry of Health and Social Welfare and joined the Department of Dermatology of Hospital Vargas. As a tribute to his fruitful efforts in our country, he was unanimously elected to receive the honorary title "Doctor Honoris Causa" from the Central University of Venezuela.

\section{The division of services and chairs}

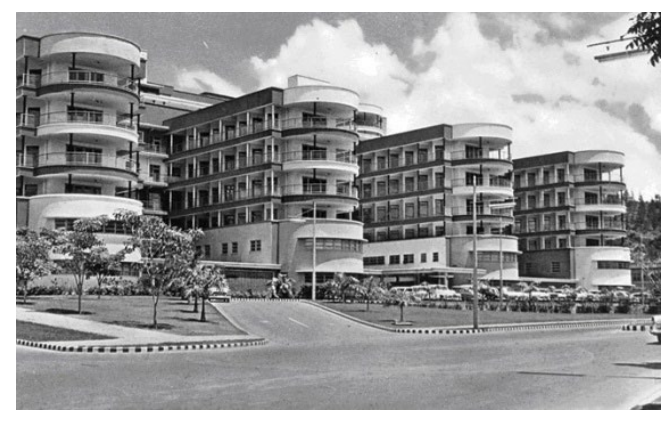

Figure 2. Central University of Venezuela.

In 1957 the School of Medicine of the Central University of Venezuela moved from the Hospital Vargas to the new University Hospital, Hospital de la Ciudad Universitaria. A new chair of dermatology was inaugurated on October 18, 1958 at the Luis Razetti Medical School and the Dermatology Service began to operate at the Caracas University Hospital with professors transferred from the Vargas Hospital, including Carlos Julio Alarcón (Professor and Chairman), Juan Di Prisco, Luís Alberto Velutini, Rafael Medina, Jacobo Obadía, Imelda Campo-Aasen, Oscar Reyes, César Lizardo, Dante Borelli and Luís Gómez-Carrasquero. The successors in the Chair of Dermatology since 1958 to this date have been: Carlos Julio Alarcón, Juan Di Prisco, Oscar Reyes, José Rafael Sardi, Homagdy Rodríguez de Arévalo, Adriana Calebotta, Omaira Castellanos de Camejo, Zulhay Torres, Francisco González-Otero, Elda Giansante, Angela Ruiz and Mary Carmen Ferreiro.

In the meantime, a secessionist movement developed between a group of professors using the old hospital facilities and the annex buildings. Doctors Jacinto Convit and Francisco Kerdel-Vegas lead the group of dermatologists together with Armando Salas and José Manuel Soto, and they organized the Chair and the service of Dermatology at the José Maria Vargas School of Medicine. There, this group established the "Association for Dermatological Research" that secured funds to invite distinguished professors of dermatology from the United States and England to teach short courses on the most important areas of the specialty. They also managed to get the support of Dr. Marion B. Sulzberger from New York University who was then about to retire. However, Dr. Sulzberger served as a liaison with Professor Eugene M. Farber from Stanford University in California. This most fruitful interaction gave origin to the new dermatology research laboratories and some time, later to the Institute of Dermatology built in the hospital surroundings. This process lasted for several years, with a considerable number of publications in international journals, invited American residents, scholarships at Stanford for Venezuelan postgraduate students, and submission of a request for approval of funds to the US National Institutes of Health; all of these actions lead to profound changes in an area of specialization that was perceived as stationary and basically morphological towards a new dynamic and functional paradigm, with considerable research efforts and the adoption of new knowledge. To mention just a few examples of the exhaustive activity undertaken in an effort to gain international recognition of this novel situation, in addition to the publication of several papers in renowned English journals, we can mention the publication of a book in English (Rhinoscleroma), the description of two new nosological entities (diffuse leishmaniasis and erythema dyschromicum perstans), and the discovery of the active principle (selenocystathionine) in the depilatory effect of the "coco de mono" (Lecythis ollaria) fruit.

The Service and Chair of Dermatology of the Vargas Hospital moved to a new building located next to the Vargas Hospital on November 29, 1971, under the name of Institute of Dermatology, than later became the "Institute of Biomedicine" (October 22nd, 1984) and in 2014 changed to the Institute of Biomedicine Dr. Jacinto Convit (Figure 3).

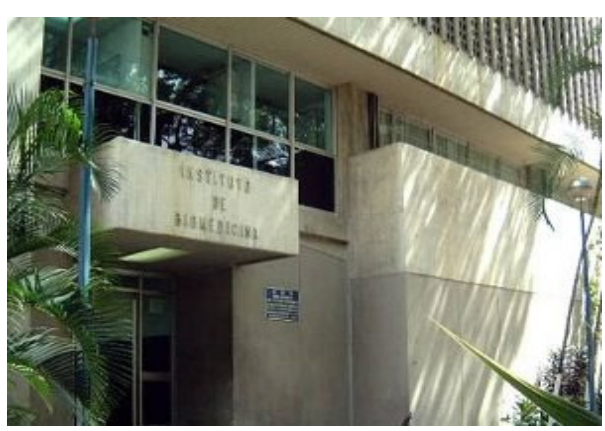

Figure 3. Institute of Biomedicine Dr. Jacinto Convit.

This institution was conceived and built as a result of the hard work and perseverance of doctors Jacinto Convit and Francisco KerdelVegas. In addition to several research laboratories, the institution provided general and specialized dermatology consultation (leprosy, mycology, pediatric dermatology, leishmaniasis, allergy, vulvar pathology, stomatology, lupus, pathology of the lower extremities, surgical pathology, laboratories of immunology, histochemistry, library, record offices, statistics and administration). The institution also runs three university graduate programs: dermatology, dermatopathology, microbiology and a master's program in tropical epidemiology. The Institute of Biomedicine, following the philosophy of its founders, 
established as a daily routine a parallel aproach of research and clinical management of the patients. This novelty atracted international interest and open the doors for the training of foreign dermatologists (from the USA).

Since its inauguration until Dr. Convit's demise (2014) the Institute of Biomedicine was under his leadership. The Service of Dermatology of the Caracas Vargas Hospital and the Chair of Dermatology of the School of Medicine are affiliates of the Institute that has been managed by Jacinto Convit, José Manuel Soto, Antonio RondónLugo, Jaime Piquero-Martín and Margarita Oliver. Similarly, the Chair of Dermatology of the School of Medicine has been under the direction of Jacinto Convit, Eva Koves de Amini, Mauricio Goihman, Antonio Rondón-Lugo and Nacarid Aranzazu.

In 1964, both the Chair of Dermatology operating at the School of Medicine, Luis Razetti, and the Chair at the School of Medicine, José María Vargas, opened Dermatology Graduate Programs following standard syllabus. The directors of the Institute of Biomedicine have been Jacinto Convit, José Manuel Soto, Antonio Rondón-Lugo and Ricardo Pérez-Alfonzo.

The first two graduate programs in Caracas (Vargas Hospital and University Hospital) were later joined with similar programs by the Service of Dermatology of the Military Hospital of Caracas, founded by Dr. Francisco Scannone and thereafter lead by Dr. Luis Alberto Velutini and Dr. Hugo Naranjo A.

Other institutions have maintained healthcare and educational activity, including the Children's Hospital, the Center of Dermatology and Allergies of the Social Security System, the "Luis Razetti" Cancer Hospital and the "Carlos J. Bello" Hospital of the Venezuelan Red Cross.

\section{Dermatology in other regions of Venezuela}

\section{Zulia (West)}

Universidad del Zulia: Dr. Jorge Hómez-Chacín created the Dermatology Chapter of the Society of Dermatology in 1956. Dermatology services were then established at several hospitals in Zulia State and undergraduate classes were administered by Drs. Hernán Vargas-Montiel, Nazario Durango and Cesar BarrosoTobila. Leopoldo Díaz-Landaeta started a pediatric dermatology graduate program.

\section{Bolívar (South)}

Universidad de Oriente: Dr. Francisco Battistini, founded in 1949 the first outpatient dermatology service in the Bolívar State. The undergraduate program began in 1960 and then the graduate dermatology residency program in 1977.

\section{Carabobo (Center)}

Universidad de Carabobo: The Dermatology Service of the Valencia Central Hospital operated under the leadership of Dr. Fernando Aguilera and as of 1968 under Dr. Raúl Fachín-Viso. In 1986, this Service became the seat of the Dermatology Chair of the Carabobo University due to the efforts of Dr. Fachín-Viso, Omar Miret, and Marco Tulio Mérida, including an ongoing dermatology graduate program.

\section{Lara (Central-Western Region)}

Universidad Centro Occidental: In 1939 Dr. Humberto Campins founded the Service of Dermatology in
Barquisimeto, Lara State, at the "Antonio María Pineda" Hospital. Doctors María Antonieta Mejías and Segundo Barroeta have been the leaders of Dermatology in the Central-Western region in Venezuela. The graduate education program opened in 1971 until 1987 when it became a university graduate program.

\section{Mérida, Táchira, Barinas (South-West)}

Los Andes Hospital: The Los Andes hospital, the anti-venereal dispensary, and the leprosy research program were founded in Merida in 1936 by Dr. Pedro Guerra-Fonseca. Later, the Chair of Dermatology took upon itself the task of imparting education in the region with the outstanding participation of Drs. Isaura Graterol and Luis Sucre in Mérida; Adolfo Vivas-Arellano in Táchira and Rolando HernándezPérez, in Barinas who is the leader of dermatology in the region.

\section{Falcón (North-West)}

The dermatology unit was inaugurated in Coro with the establishment of the "Alfredo Van Grieken University Hospital". Drs. Elsa Medina (1973), Tulio Molina Barrada (1987) and Yosely Moreno (2007) together with Dr. Maigualida Pérez have been in charge of inhospital teaching programs at the "Universidad Nacional Experimental Francisco de Miranda".

\section{The Most Relevant Personalities in Dermatology}

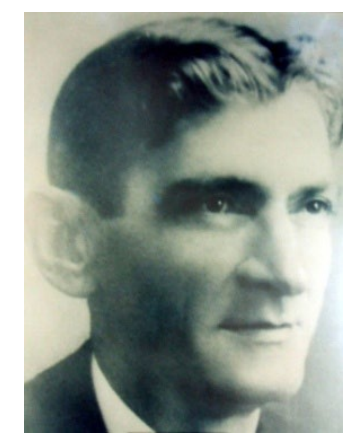

Dr. Manuel Pérez-Díaz (1872-1931): In 1903 he established the first Service of Dermatology at the Vargas Hospital. On December 30, 1908, Dr. Pérez-Díaz founded the Chair of Clinical Dermatology at the School of Medicine of Caracas. Two years later (1910), dermatology became a mandatory subject for sixth year medical students. Dr. Manuel PérezDíaz was appointed professor. In January 1903 the school acquired 37 wax dummies to illustrate the most relevant skin pathologies. These mannequins then populated the Wax Museum of Syphilography and Dermatology or the Vargas Museum were designed by the famous Jules Baretta, the same artist that created the splendid reproductions of the Saint Louis Hospital in Paris. In sum, Dr. Manuel Pérez-Díaz was the founder of Dermatology in Venezuela, a physician of the traditional school, an open-minded humanist beyond the pure stereotypes of a specialization that strongly influenced his students.

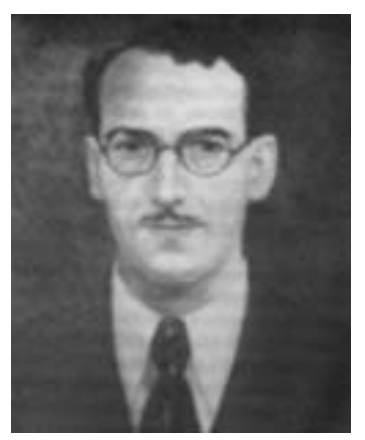


Dr. Pablo Guerra (1903-1944): Dr. Guerra studied dermatology at the Saint Louis Hospital in Paris. He returned to Venezuela in 1937 and introduced mycology, histopathology and allergology in the field of dermatology. After him dermatology was practiced based on diagnostic confirmation with direct microscopic examination, histopathological cultures and immune testing.

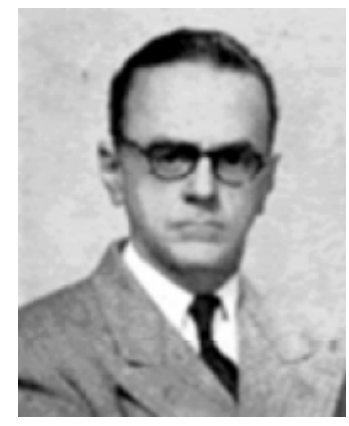

Dr. Martín Vegas (1897-1991): Dr. Vegas studied dermatology and syphilography at the Saint Louis Hospital in Paris and microbiology at the Pasteur Institute. He was the head of the Leprosy Hospital in Cabo Blanco. Member of the National Academy of Medicine. His papers on tropical diseases, leprosy, and venereal diseases were pivotal. In 1944 became the successor of Dr. Pablo Guerra as the Chair of Dermatology of the Central University of Venezuela and the corresponding service at the Vargas Hospital. His medical efforts focused on hospital care and humanitarian activities. His salary as a professor and then as Dean of the School of Medicine served to finance the mycology and histopathology laboratories of the Dermatology Service of the Vargas Hospital in Caracas. His memory still lives through the creation of the "Dr. Martín Vegas" Award and Lecture.

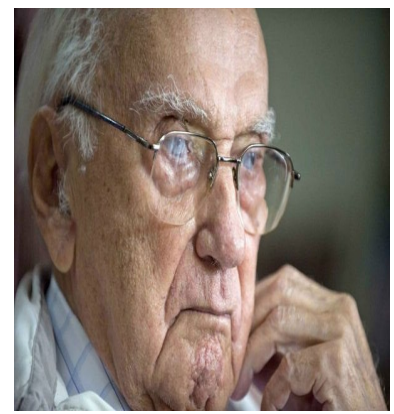

Dr. Jacinto Convit (1913-2014): Before completing his medical studies he began working at the Leprosy Hospital in Cabo Blanco where he initiated his apostleship in favor of those in need. He completed his graduate studies in dermatology at the "Skin and Cancer Hospital" (New York, USA) and then in epidemiology at the "Western Reserve University" (Cleveland, Ohio, USA). Together with some Spanish and Latin-American colleagues he founded the Iberian-Latin American College of Dermatology (CILAD) in 1948.

He worked as a Dermatologist at the Vargas Hospital since 1948, and was then appointed head of the Service and Chair of Dermatology, founder of the National Institute of Dermatology (now called after him. the Institute of Biomedicine Dr. Jacinto Convit), founder of the Association for Dermatological Research and of the Institute of Biomedicine as a biomedical research center. He promoted the clinical histopathological and immunological spectrum of dermatological diseases, particularly leprosy and leishmaniasis, in addition to management and prevention with immunoprophylaxis and immunotherapy. He practiced in private medicine for a very short term, and devoted his full time efforts to healthcare, education and research.

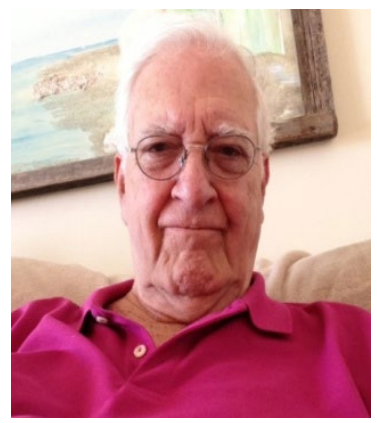

Francisco Kerdel-Vegas (1928-): Dr. Kerdel-Vegas completed his dermatology graduate studies at the Massachusetts General Hospital in Boston (Harvard Medical School) and the Skin \& Cancer Unit of New York University. He has served as a Professor of dermatology at the Central University of Venezuela, and is a member of the Academies of Medicine, and Physics, Mathematics and Natural Sciences of Venezuela; he is an Honorary Member of the National Medical Academies of Brazil, Colombia, Chile and Paraguay. He designed the dermatology exchange program with Stanford University. Dr. KerdelVegas was appointed Academic Vice Rector of the Simón Bolívar University and promoted the idea that established the scholarship project Gran Mariscal de Ayacucho of which he became a Board member. He was founder and editor of "Bitácora Médica", a healthcare Webpage / blog in Spanish. Dr. Kerdel-Vegas served as President of the International Dermatological Society; Ambassador of Venezuela in the United Kingdom, UNESCO and France. In May 1987 the International Foundation of Dermatology (IFD), affiliate of the International League of Dermatology Societies (ILDS), decided to implement a project for the development of human resources to understand and tackle the problem of skin pathologies in Africa. This exemplary project to train medical assistants at a Regional Dermatological Training Center in Moshi, Tanzania was initiated by professors, Alfred W. Kopf, Terence J. Ryan, Stuart Maddin and Henning Grossmann. After 25 years the center, at the foot of the Kilimanjaro, has trained 250 community dermatologists from 15 Africa countries and 25 specialized dermato-venereologists, and an annual intake of six residents. The physical structureis comprised of three in-patient wards with 75 beds (25 for the Burns Unit), four operation theaters, a Mohs' surgery unit, dermatopathology, teledermatology and mycology.

(The inclusion of Professor Francisco Kerdel-Vegas as one of the pillars of Dermatology in Venezuela was due to the insistency of Dr. Jaime Piquero-Martín)

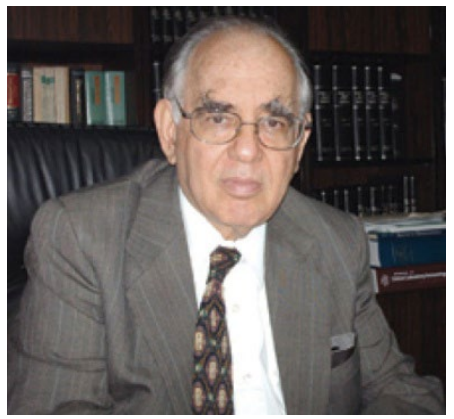


Mauricio Goihman (1938- ): Dr. Goihman completed his graduate studies in dermatology at Stanford and Miami Universities and received his PhD in Medical Microbiology from Stanford University; Professor of Dermatology and Syphilography, Vargas School of Medicine of the Central University of Venezuela. He is a Professor and the founder of immunology as part of the graduate program; Professor and Chair of Dermatology and Syphilography at the Vargas School of Medicine, a Distinguished professor of Iberian-Latin American Dermatology and of Venezuelan Dermatology, a Regional Editor of the International Journal of Dermatology, Iberian-Latin American skin medicine, International Journal of Dermatology, Dermatology Online Journal, and Clinics in Dermatology.Member of the Editorial Committee of several scientific journals, member of 24 scientific societies, author of 175 papers, 46 abstracts and 28 chapters in books. Corresponding Member of the National Academy of Medicine of Venezuela.

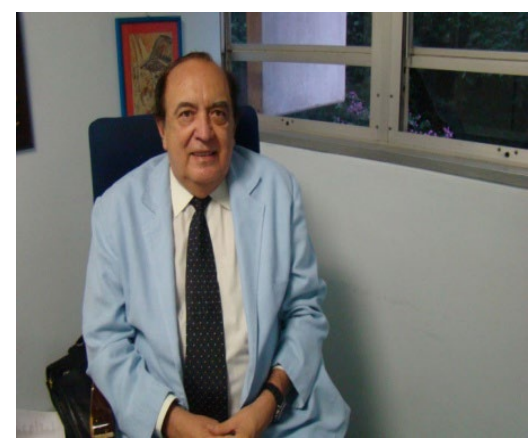

Dr. Antonio Rondón-Lugo (1939-): Emeritus Professor of the Institute of Biomedicine "Dr. Jacinto Convit" of the Central University of Venezuela; former president of the Venezuelan Society for which he served three terms; former head of the Chair of Dermatology; director of the graduate program of dermatology, in addition to an extensive list of scientific and literary publications, including books, chapters in textbooks, and articles published in national and international journals. Dr. Rondón-Lugo has actively participated in academic activities throughout Latin America as speaker at numerous conferences; he is the contemporary dermatologist with the strongest influence on the modernization of dermatology in Venezuela.

\section{The Venezuelan Society of Dermatology}

The Minister of Public Education created the Free Chair of Dermatological and Syphilographic Clinic pursuant to a decree of the Ministry of Public Education in 1908; this gave rise to the an area of specialization governed by the academia.

The Venezuelan Society of Dermatology and Syphilography was founded on November 14, 1936. The first president of the Society was Dr. Martín Vegas. Due to changes in the practice of the profession and to avoid interferences from other dermatology specialties, the Society has adopted different names at various points in time. On July 7th, 1945, the Venezuelan Society of Dermatology and Venereal Diseases; on January 7th, 1970, the Venezuelan Society of Dermatology; then in 2000, the Venezuelan Society of Dermatology and Dermatological Surgery; and finally, on December 19, 2012, adopted its current name: Venezuelan Society of Medical, Surgical and Cosmetic Dermatology.

Presently, the organization has 387 members out of a total of approximately 600 dermatologists that practice in Venezuela. The Society plays a very active role, organizing monthly meetings throughout the country, itinerant meetings, courses and congresses, in addition to various screening campaigns (Melanoma, Psoriasis and Acne). Presidents of Venezuelan Society of Medical, Surgical and
Cosmetic Dermatology from its foundation

\begin{tabular}{|c|}
\hline 1945 Rafael Campo Moreno \\
\hline 1946 Leopoldo Briceño-Iragory \\
\hline 1947 Martin Vegas \\
\hline 1949 Jacinto Convit \\
\hline 1951 Carlos Julio Alarcón \\
\hline 1952 Martin Vegas \\
\hline 1954 Rafael Medina \\
\hline 1955 Juan Di Prisco \\
\hline 1956 Francisco Scannone \\
\hline 1957 Luis Alberto Velutini \\
\hline 1058 Martin Vegas \\
\hline 1959 Oscar Reyes F. \\
\hline 1960 Porfirio Irazabal \\
\hline 1960 Luis Alberto Velutini \\
\hline 1962 Porfirio Irazabal \\
\hline 1964 Mariano Medina -Febres \\
\hline 1966 Juan Di Prisco \\
\hline 1968 Eduardo Estrada \\
\hline 1970 Francisco Kerdel-Vegas \\
\hline 1972 Jacobo Obadia-Serfaty \\
\hline 1974 Mauricio Goihman \\
\hline 1976 Jose Manuel Soto \\
\hline 1978 Cruz Graterol- Roque \\
\hline 1980 Jorge Homez- Chacin \\
\hline 1982 Eva Koves de Amini \\
\hline 1984 Antonio Rondon- Lugo \\
\hline 1986 Antonio Rondon -Lugo \\
\hline 1988 Maria Antonieta Mejias \\
\hline 1990 Jaime Piquero- Martin \\
\hline 1992 Cornelio Arevalo- Morles \\
\hline 1994 Antonio Rondon- Lugo \\
\hline 1996 Ricardo Perez - Alfonzo \\
\hline 1998 Hernan Vargas -Montiel \\
\hline 2000 Francisco Gonzalez- Otero \\
\hline 2002 Alfredo Lander \\
\hline
\end{tabular}


2004 Benjamin Trujillo

2006 Rolando Hernandez- Perez

2008 Elda Giansante

2010 Elda Giansante

2012 Nahir Loyo

\section{Maria Esther Chirinos}

The dermatological specialty has maintained an active academic participation with dermatology meetings organized not only by the Society of Dermatology, but also by independent groups under the sponsorship of the Society. Such is the case of the meeting of the "Group of Dermatologic Therapy Update" organized by Drs. Antonio Rondón-Lugo, Jaime Piquero-Martín and Ricardo PérezAlfonzo and the meetings on "Pediatric Dermatology" organized by Dr. Francisco González.

\section{Regular publications}

The Journal of Venezuelan Dermatology was founded, under Dr. Luis Alberto Velutini's initiative (the first Editor), in December 1957. This is the official publication of the Venezuelan Society of Dermatology that has undertaken a steady and continuous effort to promote the specialty and is currently available through Internet.

In 1998 Drs. Jaime Piquero-Martín, Rolando HernándezPérez and Félix J. Tapia founded the digital Journal "Piel Latinoamericana", posted every weeks at www.Piel-l.org with over 12,000 subscribers in Spain and Latin America. Similarly, Dr. Francisco González-Otero, edits the blog "Dermatología Pediátrica" www. Dermatologiapediatica.net, and professor Francisco Kerdel-Vegas, publishes the medical blog "BitácoraMédica" www.bitacoramedica. com.

\section{Sub-specialties}

Leprosy: The Cabo Blanco Leprosy Clinic was inaugurated in 1906, located by the coast, in the Vargas State. Dr. Aaron Benchetrit was appointed Inspector General of the Leprosy Clinics of the Republic in 1909, under the Ministry of Internal Affairs. He held that position for many years, in charge the leprosy clinics at Cabo Blanco and later a second facility located at the Providencia Isle on the Maracaibo Lake. These specialized clinics are no longer operational so any patient affected by the disease that may require care is admitted to a general hospital. The most relevant physicians in this area have been Martín Vegas, Jacinto Convit, Nacarid Aranzazu, Pedro La Penta and Enrico Rassi.

Sexually Transmitted Diseases: The first healthcare institution for sexually transmitted disease was established in 1926, and in 1939 became the Division of Venereal Diseases of the Ministry of Health, under the leadership of Dr. Martín Vegas. Training programs for venereal specialists were initially offered. At a later date, Drs. Martin Vegas and Rafael Medina founded the National Institute of Venereal Diseases. Other relevant physicians in the area included Drs. Ildemaro Lovera, Cornelio Arévalo, José R. Sardi and Mary Carmen Ferreiro.

Dermatopathology: Following the foundation of the Service of Dermatology of the Caracas University Hospital in 1957, dermatology became a sub-specialty under the leadership of Dr. Oscar Reyes-Flores. In addition to Professor Reyes, other outstanding personalities in Venezuela include Drs. Hugo Naranjo, César Barroso, Marco Tulio Mérida and Gustavo Rodríguez-Garcilazo, and the present head of dermato-pathology at the Caracas University Hospital, Dr. Elizabeth Ball. At the Institute of Biomedicine Dr. Margarita Oliver is the Director of the graduate program of dermato-pathology.

Mycology: Dr. Pablo Guerra founded the first mycology laboratory in 1940. This area of specialization was initially organized by professors Dante BoreIli, Humberto Campins, María Cecilia Albornoz, Jorge Hómez-Chacín, Carmen Marcano and Hernán Vargas-Montiel. The group of mycologists has been very active, organizing working groups to study mycoses in Venezuela and publishing the newsletter "Las Micosis en Venezuela" (Mycoses in Venezuela).

Pediatrics: Dr. Eva Koves de Amini at the Institute of Biomedicine initially promoted this subspecialty; later on, Dr. Luis A. González A. established a clinic for pediatric dermatology at the Pérez-Carreño Hospital and then Dr. Esther Wackzol opened the pediatric dermatology clinic at the "J. M. de los Ríos" Children's Hospital in Caracas. Dr. Francisco González was the founder of the Pediatric Dermatology Clinic at the Department of Dermatology of the University Hospital of Caracas. A Graduate Pediatric Dermatology Program is currently available at the Zulia University, under the leadership of Dr. Leopoldo Díaz-Landaeta.

Immunology: Drs. Juan DiPrisco and Mauricio GoihmanYahr introduced the specialty of immunology to Dermatology and completed valuable research projects at the Caracas University Hospital and at the Institute of Biomedicine. Drs. J. F. Tapia, Marian Ulrich, María Cristina di Prisco and Nieves González continued with this line of work.

Dermatological surgery: This area of specialization began to develop late in the 70's with Dr. VíctorSuprani and then Drs. José Rafael Sardi and Marina Chopite were instrumental in promoting its important growth. Gilberto Castro-Ron is recognized around the world for his work in cryosurgery.

\section{Epilogue}

History is valuable in as much as it helps us to understand the past and fit together possible hypothesis about the immediate future. Hence, what we have written about the history of dermatology in Venezuela makes sense, as an example or role model for other countries under similar conditions. How a small group of people were able to drastically change the future of a medical specialty (dermatology), disrupting a model of apparent stability and complacency, and change for a new paradigm of progress and advancement; thus, in just a few years, reaching out for national and international support, designing an action plan that was meticulously implemented in successive and wellthought stages (in consultation with some qualified and internationally acknowledged friends), it was possible to provide a solid scientific research-based foundation to the practice of dermatology. This is no extraordinary deed, except for the fact that these changes took place in a small Latin American country, where ground-breaking successes are the exception and not the rule.

Hence the moral of the story for the new generations of physicians: never give up on a noble goal. Use what one of us has called the "battering ram strategy": keep hammering on the same spot until you overcome resistance.

When we were asked to write this chapter on the History of Dermatology, we did not hesitate to accept the challenge since we thought that we could unassumingly convey interesting information and share with numerous colleagues throughout the developing 
world, who are struggling to contain skin diseases and are eagerly searching for ways and means to succeed in their quest. We do not claim to have all the answers, just a modest success story that may be used as a lesson and an incentive to those who share the same ideals.

\section{References}

1. Archila R (1961) Historia de la Medicina en Venezuela, Tipografía Vargas, Caracas.

2. Scannone F (1990) Historia de la Dermatología en Venezuela, Editorial Cromotip, Caracas.

3. Briceño Maaz T (1978) Datos para la historia de la Dermatología en Venezuela. Derm Ven 16: 29-40.
4. Briceño Maaz T (1991) Esbozo histórico de la Dermatología en el Hospital Vargas de Caracas". Derm Ven 29: 23-24.

5. Rondón Lugo AJ, Sáenz Astort JA (2001) Aproximación histórica a la dermatología Venezolana, Producción Excelsior, Caracas.

6. Lander A, Piquero Martin J, Rondón Lugo A, Reyes Flores O, Trujillo B, et al (2007) Historia de la Dermatología en Venezuela. Historia de la Dermatología Latinoamericana. Editions Privat: 427-444.

7. Kerdel Vegas F (2014) The path to modernity: A personal testimony to the restructuring of the Department of Dermatology, Vargas Hospital, Caracas, Venezuela Clinics in Dermatology 32: 320-323.

Copyright: $(2015$ Kerdel-Vegas F. This is an open-access article distributed under the terms of the Creative Commons Attribution License, which permits unrestricted use, distribution, and reproduction in any medium, provided the original author and source are credited. 